\title{
Nanoscale Patterning and Welding by Solvent-free Dry Particle Spray and Focused Ion Beam
}

\author{
Jung-Oh Choi' and Chung-Soo Kim ${ }^{1,2, t}$ \\ 1 School of Mechanical \& Aerospace Engineering, Building 301, Room 1405, Seoul National University, San 56-1, Shinlim-Dong, Kwanak,-Gu, Seoul, Korea, 151-742 \\ 2 Research Laboratory of Electronics, Massachusetts Institute of Technology, 77 Massachusetts Ave, Cambridge, MA, USA, 02139 \\ \# Corresponding Author / E-mail: reaves.kim@gmail.com, TEL: +82-2-886-9074, FAX: +82-2-883-0179
}

KEYWORDS: Solvent-free dry particle spray, Nano particle deposition system, Nanoscale patterning, Nanoscale welding

\begin{abstract}
Nano particle deposition system (NPDS) is one of dry particle spray methods such as cold spray and aerosol deposition. It can be used to build structures from metals, ceramics, and nanomaterials without any solvents at room temperature and under low vacuum conditions, reducing energy consumption. Recent advances in dry particle spray techniques, including NPDS, have demonstrated their use with advanced nanomaterials such as carbon nanotube. However, to date, this process has not been successfully scaled down to 100-nm scales. Here, we demonstrate the use of NPDS as dry particle spray method in the nanoscale regime with the help of a focused ion beam for nanoscale manufacturing. Nanoscale patterning and welding were achieved using a nano particle deposition system with miniaturized feature sizes that were smaller than $100 \mathrm{~nm}$ in scale.
\end{abstract}

Manuscript received: May 13, 2014 / Revised: May 18, 2014 / Accepted: May 19, 2014

\section{Introduction}

Recently, environmental effects and energy consumption have become pressing issues for manufacturing industries, in addition to precision, accuracy, and speed, due to tough environmental regulations and the costs of high energy consumption. ${ }^{1-4}$ Solvent-free manufacturing processes have become important to minimize environmental damage and hazardous material consumption, avoiding the use of solvents such as alcohol, acetone, toluene, or xylene. Several types of solvent-free manufacturing processes are in existence, such as physical vapor deposition and dry powder spraying. Spraying methods, such as cold spraying, aerosol deposition, and nanoparticle deposition system (NPDS), provide a low-temperature process with the advantages of low energy consumption and high deposition rates. ${ }^{5}$

Cold spraying can be used to deposit metals and metal-matrix composites through a nozzle at a high deposition rate to achieve materials with low porosity, low oxidization, and low residual stresses by accelerating the particles with a highly pressurized gas without melting them before impact with the substrate.$^{6-8}$ Aerosol deposition uses aerosols by combining ultra-fine metal and metal oxide particles with a carrier gas at room temperature. ${ }^{9-11}$ NPDS were developed to build different materials, such as metals and metal oxides, on various substrates using cold spraying and aerosol deposition. ${ }^{5}$ Compared with other dry spray processes, NPDS have the advantages of low energy consumption and few system requirements, as they avoid high vacuums and high-pressure gases. ${ }^{12-14}$

Using these dry particle spray methods, single materials, multimaterials, and mixtures of metal/metal and metal/ceramic and nanomaterials such as graphene, nanotube, and so on can be formed as films on various substrates. ${ }^{10,15,16}$ However, nanomanufacturing capability has not yet been demonstrated for dry particle sprays, although various researchers have investigated particle-based deposition for a variety of purposes.

Here, the scaling-down of the manufacturing regime for solvent-free dry particle sprays is proposed by NPDS. Nanoscale substrate damage was investigated with both metal and ceramic particles, and methods for patterning and welding in the nanoscale regime are demonstrated.

\section{Nanoscale Damage}

Significant damage to the substrate can occur during conventional cold spraying or aerosol deposition. ${ }^{9,17,18}$ Thus, it is difficult or impossible to engineer a nanoscale surface using these manufacturing techniques. However, an NPDS has non-invasive deposition characteristics, as demonstrated by observing cross-sections with 

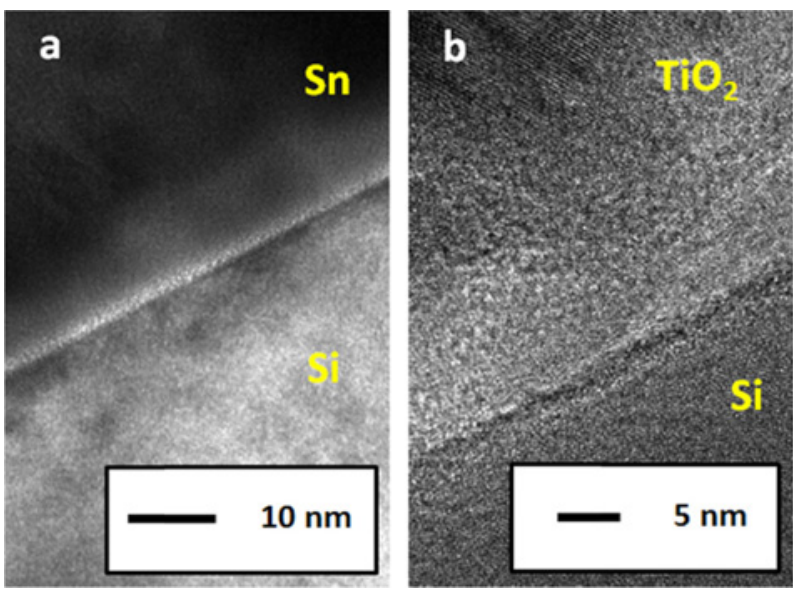

Fig. 1 Interfaces between films and silicon substrates: (a) metal film$\mathrm{Sn}$ on $\mathrm{Si}$ and (b) ceramic film- $\mathrm{TiO}_{2}$ on $\mathrm{Si}$

scanning electron microscopy, ${ }^{19}$ which shows no damage on the polymer surface.

For successful nanoscale deposition, the substrate damage from an NPDS must be almost zero or in the range of tens of nanometers. Here, a focused ion beam (FIB) was used to assist the NPDS, and transmission electron microscopy (TEM) techniques were implemented to observe the nanoscale damage between the film and substrate. To verify the damage caused by metal and ceramic particles, $\mathrm{Sn}$ and $\mathrm{TiO}_{2}$ were deposited onto $\mathrm{Si}$ substrates. Each $\mathrm{Sn}$ and $\mathrm{TiO}_{2}$ particle had diameters of 2-20 mm (Sigma-Aldrich) and $15 \mathrm{~nm}$ (Nanoarmor), respectively. The interfaces of the $\mathrm{Sn}$ and $\mathrm{TiO}_{2}$ films on the $\mathrm{Si}$ substrates are shown in Fig. 1. The $\mathrm{Sn}$ and $\mathrm{TiO}_{2}$ films formed by the NPDS caused no critical visible damage at sub-5-nm scales, and both the metal and ceramic particles adhered to the substrate well.

\section{Nanoscale Application}

\subsection{Nanoscale Patterning}

To create a nanoscale structure using a dry particle spray, a nanoscale template first was prepared on a silicon substrate using an FIB. This nanoscale template consisted of V-grooves with mouth widths of 700, 350, and $250 \mathrm{~nm}$ that were fabricated by FIB milling and material redeposition. ${ }^{20}$ The dry particle spray was applied to the substrate using $\mathrm{Sn}$ and $\mathrm{TiO}_{2}$ particles. The carrier gas was air, with a relative air pressure of $0.3 \mathrm{MPa}$, chamber pressure of $-0.097 \mathrm{MPa}$, feed rate of $0.025 \mathrm{~mm} / \mathrm{s}$, and stand-off distance of $3 \mathrm{~mm}$. A TSI $3400 \mathrm{~A}$ powder feeder was used to supply the particles to the deposition system.

An FIB cross-section technique was used to verify the crosssections of the patterned $\mathrm{Sn}$ and $\mathrm{TiO}_{2}$, as shown in the image of Fig. 2 , which was obtained by scanning ion microscopy (SIM). The Sn and $\mathrm{TiO}_{2}$ particles were evenly packed inside the smallest V-grooves, where the mouth width was $250 \mathrm{~nm}$. These results indicate that both particles can be used to form $<100$-nm nanostructures at the apex of V-grooves. However, the particles were packed at different densities. For Sn, the nanostructure inside the V-groove observed by SIM ion channeling indicated that the ductile $\mathrm{Sn}$ particles experienced high strain rate
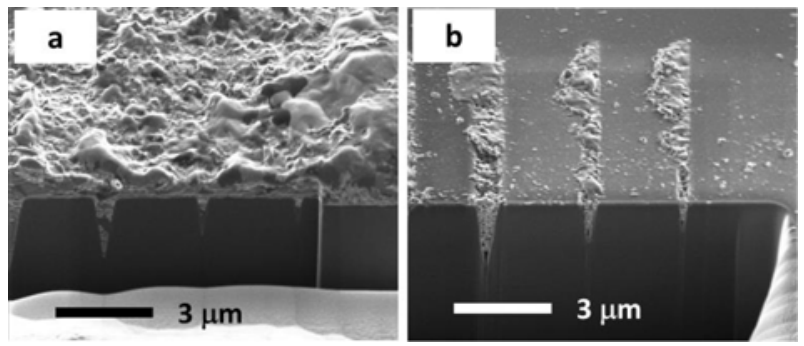

Fig. 2 Nanoscale patterning by dry particle spraying assisted by FIB: (a) metallic nanostructures of $\mathrm{Sn}$ and (b) ceramic nanostructures of $\mathrm{TiO}_{2}$ on silicon substrates

a
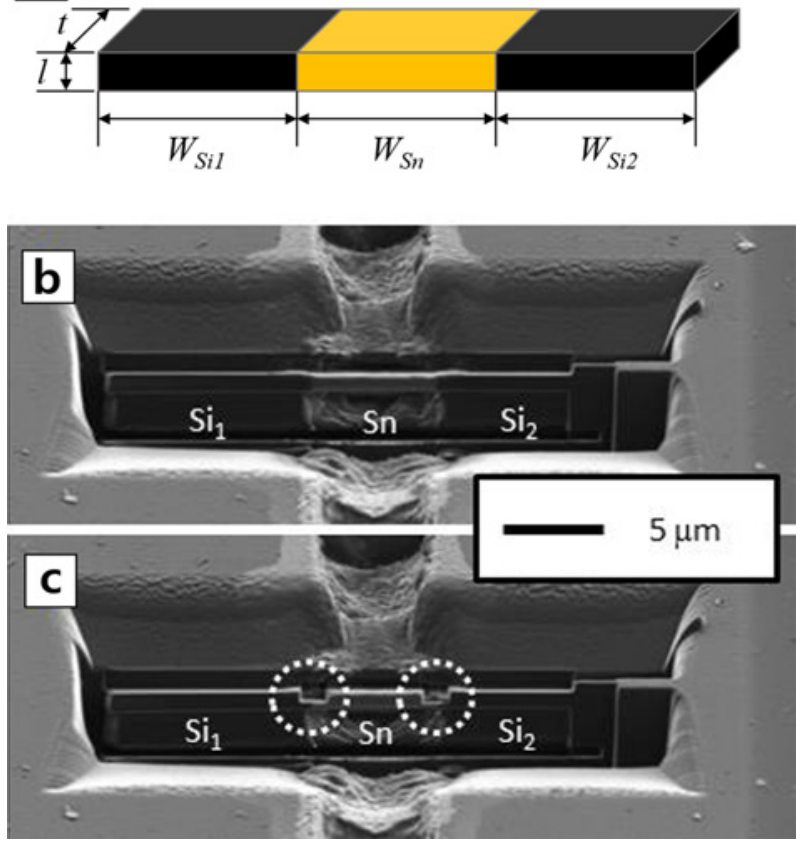

Fig. 3 Nanoscale welding by dry particle spraying assisted by FIB: a $\mathrm{Si}-\mathrm{Sn}-\mathrm{Si}$ freestanding nanoscale cantilever

deformation and finally formed smaller grains, each with crystal orientations different from that of the original Sn particles.

It is noteworthy that the ductile metallic particles used to form the nanostructure could be larger than the V-groove. This is valuable in terms of manufacturing cost, as the micro-sized Sn particles could be sprayed to form nanostructures without requiring the high cost of nanosized materials.

Unlike Sn metallic nanostructures, the $\mathrm{TiO}_{2}$ nanostructures in the Vgrooves had a porous structure, even though the size of $\mathrm{TiO}_{2}$ particles was much smaller than the FIB-milled pattern width.

\subsection{Nanoscale Welding}

Nanoscale welding was implemented through the following procedure: (1) a 5-mm-wide pattern was milled on Si substrate by FIB; (2) Sn particles were deposited on the FIB-milled area; and (3) FIBmilling of both $\mathrm{Si}$ and $\mathrm{Sn}$ was used to shape a Si-Sn-Si cantilever.

Fig. 3 shows the nanoscale welding result obtained using an NPDS assisted by an FIB. The thickness $(t)$ of the cantilever was $100 \mathrm{~nm}$, the length $(l)$ was $350 \mathrm{~nm}$, and the widths of $\mathrm{Si}_{1}, \mathrm{Sn}$, and $\mathrm{Si}_{2}$ were 10, 6.3, 
and $6.3 \mathrm{~mm}$, respectively, as shown in Fig. 3a-c. The FIB milled more material at both the $\mathrm{Si}_{1} / \mathrm{Sn}$ and the $\mathrm{Sn} / \mathrm{Si}_{2}$ interface. Therefore, the length of the welded part was only around $175 \mathrm{~nm}$ (dotted circles in Fig. 3c). In this region, the contact area between the $\mathrm{Sn}$ and $\mathrm{Si}$ was only $0.017 \mathrm{~mm}^{2}$. It is noteworthy that the NPDS could create a freestanding nanostructure with multi-materials at room temperature with no thermal process such as high-temperature sintering. This could be used for many applications, particularly in flexible membrane structures.

\section{Conclusions}

This paper described how the environmentally friendly dry particle spray method could be scaled down to the nanoscale manufacturing regime. As a demonstration, a solvent-free NPDS, which is a dry particle spraying method, was utilized along with an FIB. First, we showed that there was no significant nanoscale substrate damage due to particle impacts. Then, we proposed two different types of nanomanufacturing processes, nanoscale patterning and joining, and used an NPDS to illustrate how a dry particle spray could be applied to a nanomanufacturing process. The NPDS created metallic sub-100$\mathrm{nm}$ nanostructures inside V-grooves. We also fabricated a freestanding nanostructure with a very small welded area of $0.017 \mathrm{~mm}^{2}$.

Future research is planned to determine the mechanism of nanoscale particle packing and adhesion as well as the manufacturing resolution and aspect ratio limits of this process.

\section{ACKNOWLEDGEMENT}

This work was supported by National Research Foundation (NRF) grant funded by the Korea Government (MEST) No. NRF-20100029227, and this work was supported by the Brain Korea 21 Plus Project in 2014.

\section{REFERENCES}

1. Lipomi, D. J., Wdiss, E. A., and Whitesides, G. M., "Green Nanofabrication: Unconventional Approaches for the Conservative Use of Energy," in: Nanotechnology for the Energy Challenge, Martínez, G., (Ed.), Wiley-VCH Verlag GmbH \& Co. KGaA, pp. 229-279, 2010.

2. Duflou, J. R., Sutherland, J. W., Dornfeld, D., Herrmann, C., Jeswiet, J., et al., "Towards Energy and Resource Efficient Manufacturing: A Processes and Systems Approach," CIRP AnnalsManufacturing Technology, Vol. 61, No. 2, pp. 587-609, 2012.

3. Abele, E., Anderl, R., and Birkhofer, H., "Environmentally-friendly Product Development," Springer, 2005.

4. Chun, D. M., Choi, J. O., Lee, C. S., Kanno, I., Kotera, H., et al., "Nano-particle Deposition System (NPDS): Low Energy Solventfree Dry Spray Process for Direct Patterning of Metals and Ceramics at Room Temperature,” Int. J. Precis. Eng. Manuf., Vol. 13, No. 7, pp. 1107-1112, 2012.
5. Chun, D. M., Kim, M. H., Lee, J. C., and Ahn, S. H., "Nano Particle Deposition System (NPDS) for Ceramic and Metal Coating at Room Temperature and Low Vacuum Condition," Proc. of the ICSMA International Conference on Smart Manufacturing Application, pp. 383-386, 2008.

6. Wang, Q., Spencer, K., Birbilis, N., and Zhang, M. X., "The Influence of Ceramic Particles on Bond Strength of Cold Spray Composite Coatings on AZ91 Alloy Substrate," Surface and Coatings Technology, Vol. 205, No. 1, pp. 50-56, 2010.

7. Chun, D. M., Kim, C. S., Choi, J. O., Lee, G. Y., Lee, C. S., et al., "Multilayer Deposition of Ceramic and Metal at Room Temperature using Nanoparticle Deposition System (NPDS) and Planarization Process," International Journal of Advanced Manufacturing Technology, Vol. 72, No. 1-4, pp. 41-46, 2014.

8. Lupoi, R. and O'Neill, W., "Deposition of Metallic Coatings on Polymer Surfaces using Cold Spray," Surface and Coatings Technology, Vol. 205, No. 7, pp. 2167-2173, 2010.

9. Ghelichi, R., MacDonald, D., Bagherifard, S., Jahed, H., Guagliano, M., et al., "Microstructure and Fatigue Behavior of Cold Spray Coated AL5052," Acta Materialia, Vol. 60, No. 19, pp. 6555-6561, 2012.

10. Piechowiak, M. A., Henon, J., Durand-Panteix, O., Etchegoyen, G., Coudert, V., et al., "Growth of Dense $\mathrm{Ti}_{3} \mathrm{SiC}_{2} \mathrm{MAX}$ Phase Films Elaborated at Room Temperature by Aerosol Deposition Method," Journal of the European Ceramic Society, Vol. 34, No. 5, pp. 1063 1072, 2014.

11. Akedo, J., "Room Temperature Impact Consolidation (RTIC) of Fine Ceramic Powder by Aerosol Deposition Method and Applications to Microdevices," Journal of Thermal Spray Technology, Vol. 17, No. 2, pp. 181-198, 2008.

12. Kim, C. W., Choi, J. H., Kim, H. J., Lee, D. W., Hyun, C. Y., et al., "Effects of Interlayer Roughness on Deposition Rate and Morphology of Aerosol-deposited $\mathrm{Al}_{2} \mathrm{O}_{3}$ Thick Films," Ceramics International, Vol. 38, No.7, pp. 5621-5627, 2012.

13. Kim, M. S., Chun, D. M., Choi, J. O., Lee, J. C., Kim, K. S., et al., "Room Temperature Deposition of $\mathrm{TiO}_{2}$ using Nano Particle Deposition System (NPDS): Application to Dye-sensitized Solar Cell (DSSC)," Int. J. Precis. Eng. Manuf., Vol. 12, No.4, pp. 749752, 2011.

14. Ahn, S. H., Chun, D. M., and Kim, C. S., "Nanoscale Hybrid Manufacturing Process by Nano Particle Deposition System (NPDS) and Focused Ion Beam (FIB)," CIRP Annals-Manufacturing Technology, Vol. 60, No. 1, pp. 583-586, 2011.

15. Chun, D. M. and Ahn, S. H., "Deposition Mechanism of Dry Sprayed Ceramic Particles at Room Temperature using a Nanoparticle Deposition System," Acta Materialia, Vol. 59, No. 7, pp. 2693-2703, 2011.

16. Bakshi, S. R., Singh, V., Balani, K., McCartney, D. G., Seal, S., et al., "Carbon Nanotube Reinforced Aluminum Composite Coating 
via Cold Spraying," Surface and Coatings Technology, Vol. 202, No. 21, pp. 5162-5169, 2008.

17. Inada, R., Shibukawa, K., Masada, C., Nakanishi, Y., and Sakurai, Y., "Characterization of As-deposited $\mathrm{Li}_{4} \mathrm{Ti}_{5} \mathrm{O}_{12}$ Thin Film Electrode Prepared by Aerosol Deposition Method," Journal of Power Sources, Vol. 253, pp.181-186, 2014.

18. Klinkow, S. V., Kosarev, V. F., and Rein, M., "Cold Spray Deposition: Significance of Particle Impact Phenomena," Aerospace and Technology, Vol. 9, No. 7, pp.582-591, 2005.

19. Ahn, S. H., Choi, J. O., Kim, C. S., Lee, G. Y., Lee, H. T., et al, "Laser-assisted Nano Particle Deposition System and Its Application for Dye Sensitized Solar Cell Fabrication," CIRP AnnalsManufacturing Technology, Vol. 61, No. 1, pp. 575-578, 2012.

20. Kim, C. S., Ahn, S. H., and Jang, D. Y., "Review: Developments in Micro/Nanoscale Fabrication by Focused Ion Beams," Vacuum, Vol. 86, No. 8, pp.1014-1035, 2012. 